\title{
Skin Punch Biopsies and Lymphocytes in the Diagnosis of Lipidoses
}

\author{
C. L. DOLMAN, P. M. MacLEOD AND E. CHANG
}

SUMMARY: Skin punch biopsies and buffy coats of white blood cells were examined electron microscopically in patients suffering from a variety of storage diseases. No specific abnormalities could be detected in Gaucher's disease and adreno-leucodystrophy. While characteristic deposits were found in cutaneous nerves in globoid and metachromatic leucodystrophy, this method was deemed inferior to sural nerve biopsy. In gangliosidoses, on the other

RÉSUMÉ: Une biopsie punctiforme de la peau et les globules blancs ont été examinés au microscope électronique chez des patients souffrant d'une variété de maladies de storage. Aucune anomalie spécifique n'a été trouvée dans la maladie de Gaucher ou dans l'adrénoleucodystrophie. Malgré que des dépôts caractéristiques aient été trouvés dans les nerfs cutanés dans les leucodystrophies globoides et métachromatiques, cette méthode est considérée comme inférieure à la biopsie du nerf sural. Dans les gangliosidoses, d'autre part, les hand, pathognomonic membranous cytoplasmic bodies were common in axons of cutaneous nerves, and in generalized gangliosidoses marked vacuolation of many other cells was prominent. Specific deposits were found in various cells in skin punch biopsies and in lymphocytes of children suffering from ceroid lipofuscinoses, and in lymphocytes of their parents. This constitutes the easiest diagnostic laboratory procedure in such cases.

corps cytoplasmiques membraneux pathognomoniques étaient communs dans les axones des nerfs cutanés. Dans les gangliosidoses généralisées, une vacuolisation de plusieurs autres cellules était présente. Des dépôts spécifiques ont été trouvés dans plusieurs cellules au niveau des biopsies cutanées ainsi que dans les lymphocytes chez des enfants souffrant de lipofuscinoses céroides et les lymphocytes de leurs parents. Ceci constitue la procédure de laboratoire diagnostique la plus facile dans ces cas.
The exact diagnosis of many lipidoses is often made in the laboratory of the biochemist. Where histological study is indicated, tissues may be used which are more accessible than the brain. Thus, the advent of rectal biopsy has permitted the examination of autonomic neurons involved in neuronal storage diseases. Further, peripheral nerve contains characteristic deposits in metabolic disorders of white matter such as metachromatic or globoid leucodystrophy. In some diseases, particularly the chemically ill-defined groups known as "Batten-Spielmeyer-Vogt disease," "neuronal ceroid lipofuscinosis," "lipidoses with curvilinear or fingerprint profiles," or "cerebral lipidosis with onset past infancy" (Dekaban and Herman, 1974), storage is common in many organs.

Carpenter, Karpati and Andermann (1972) pointed out the usefulness of skin biopsies in these diseases, and this was confirmed by Martin and Jacobs (1973). Vacuolization of lymphocytes in patients with Spielmeyer-Vogt disease and their relatives was first described by Bagh and Hortling (1948). Witzleben $(1971,1972)$ found specific fingerprint profiles in vacuolated lymphocytes of two afflicted brothers and their parents. Our paper describes the electron microscopic findings in skin punch biopsies and lymphocytes of a number of patients with various inborn errors of metabolism.

\section{METHODS}

Skin punch biopsies were taken from the deltoid region after local infiltration with a 2,3 , or $4 \mathrm{~mm}$. skin punch, at once fixed in $2.5 \%$ glutaraldehyde and later changed to

\footnotetext{
Reprint requests to Dr. C. L. Dolman, Department of Pathology, Vancouver General Hospital, 855 West 12th Avenue, Vancouver, B.C.. Canada

V5Z $1 \mathrm{M} 9$.

From the Departments of Pathology and Medical Genetics, the Vancouver General Hospital and the University of British Columbia, Canada.
} 


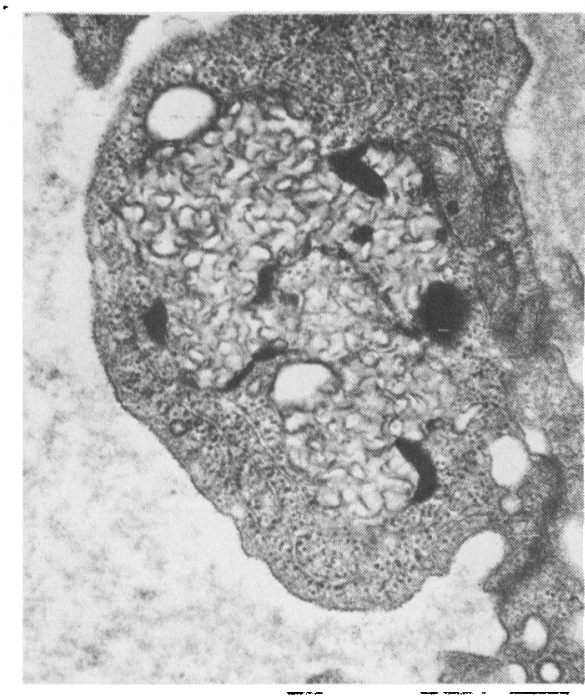

Figure 1-Ceroid lipofuscinosis, case 3. Skin punch biopsy. An endothelial cell is filled with curvilinear cytosomes. $x$ 40.600

buffer. A central slice, at right angle to the surface, was cut and divided into 9 blocks which were embedded in plastic. Suitable blocks, containing nerves, vessels, smooth muscle and skin appendages, were selected from $i \mu$ sections and about 1-3 blocks were prepared for electron microscopy. Initially, a portion of the skin punch biopsy was embedded in paraffin for light microscopy. Results were disappointing because

Figure 2-Ceroid lipofuscinosis, case 7. Skin punch biopsy. Granular osmiophilic deposits in smooth muscle cell. $\times 31.100$

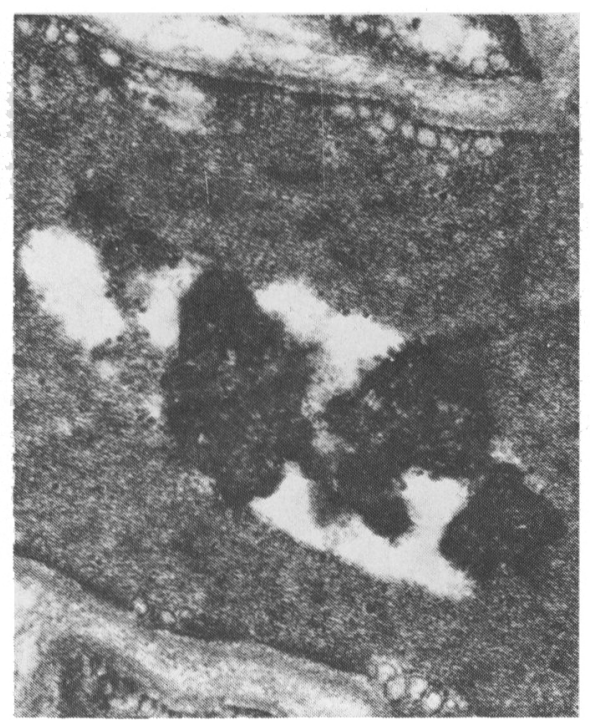

of the small size of the biopsy and this method was abandoned. Occasionally another skin punch biopsy was taken for fibroblast culture.

Three ml. of venous blood were drawn, mixed with $6 \mathrm{ml}$. of dextran and left standing for 45 minutes. The buffy coat was aspirated and centrifuged, resuspended in hypotonic saline to dissolve the red cells, made isotonic with hypertonic saline and centrifuged. This process was repeated three times. The pellet thus obtained was fixed in $0.4 \mathrm{ml}$. of $2.5 \%$ glutaraldehyde and then prepared for thin sections in the usual way.

\section{CEROID LIPOFUSCINOSES}

Ten children were classified under this general heading. They had late infantile or juvenile onset of psychomotor retardation of varying degree, myoclonus, seizures, and failing vision, often due to retinitis pigmentosa. Eight patients had skin punch biopsy and white blood cell examination; one, skin punch biopsy only, and the tenth only white cell examination, since the mother refused skin biopsy. Skin samples were available from the parents of two children; white cells from both parents of one and from the father of the other. Cultured fibroblasts were obtained in three patients for electron microscopy. Three children had positive brain biopsies, two had positive rectal biopsies and one had a sister whose tissues at necropsy were filled with curvilinear cytosomes.

The cytoplasmic inclusions fell into three broad groups. Five children with late infantile onset had membrane-bound deposits of curvilinear cytosomes in addition to occasional clumps of nonspecific granules. The other two patients had amorphous dark osmiophilic deposits. One of these was definitely microcephalic, the other was on a low normal percentile for head size. Such amorphous deposits were described in microcephalic infants by Haltia et al (1973), and in a juvenile case by Carpenter et al (1973).

The three older cases showed fingerprint patterns, longer membranes or tubular inclusions. All nine skin punch biopsies showed the characteristic inclusions in a variety of tissues, such as endothelial (Fig. 1) and perithelial cells, Schwann cells, smooth muscle (Fig. 2), and the epithelium of skin appendages. Skin biopsies of the four parents were negative. Fibroblast cultures from the skin did not contain any abnormal deposits.

Blood smears were available on five children and one parent. Vacuolated lymphocytes were present in two juvenile cases, in one of the patients with osmiophilic deposits, and in the father of a child with curvilinear cytosomes. None could be found in two children with curvilinear profiles. On electron microscopy, however, pathognomonic deposits were present in the cytoplasm of lymphocytes in all the nine patients examined, and these matched in morphology the inclusions seen in the corresponding skin biopsy (Figs. 3, 4, 5, 6). The three parents also had abnormal inclusions in the lymphocytes, but while those of their children contained curvilinear profiles, the parents' lymphocytes had fingerprint and tubular shapes (Fig. 7).

These cases are summarized in Table 1. Their clinical and epidemiological background will be detailed in a separate paper.

Figure 4-Ceroid lipofuscinosis, case 6. Lymphocyte containing granular osmiophilic deposits. $x 20.300$

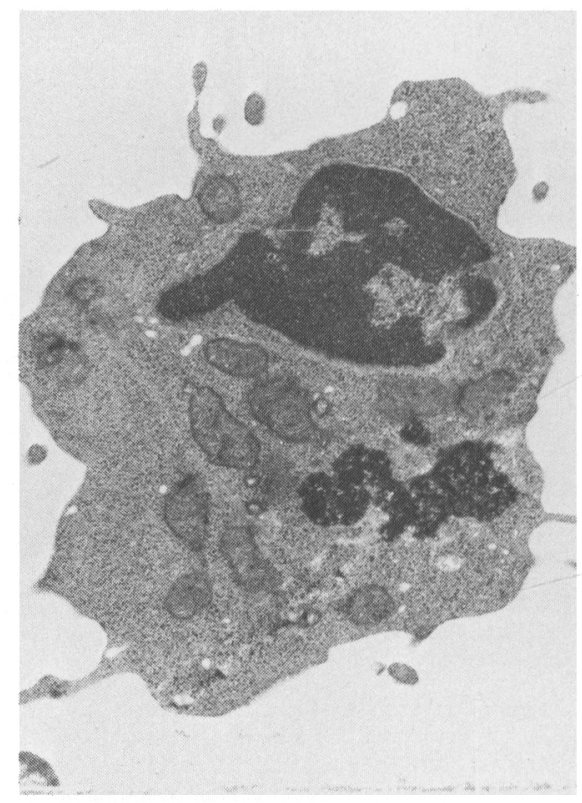




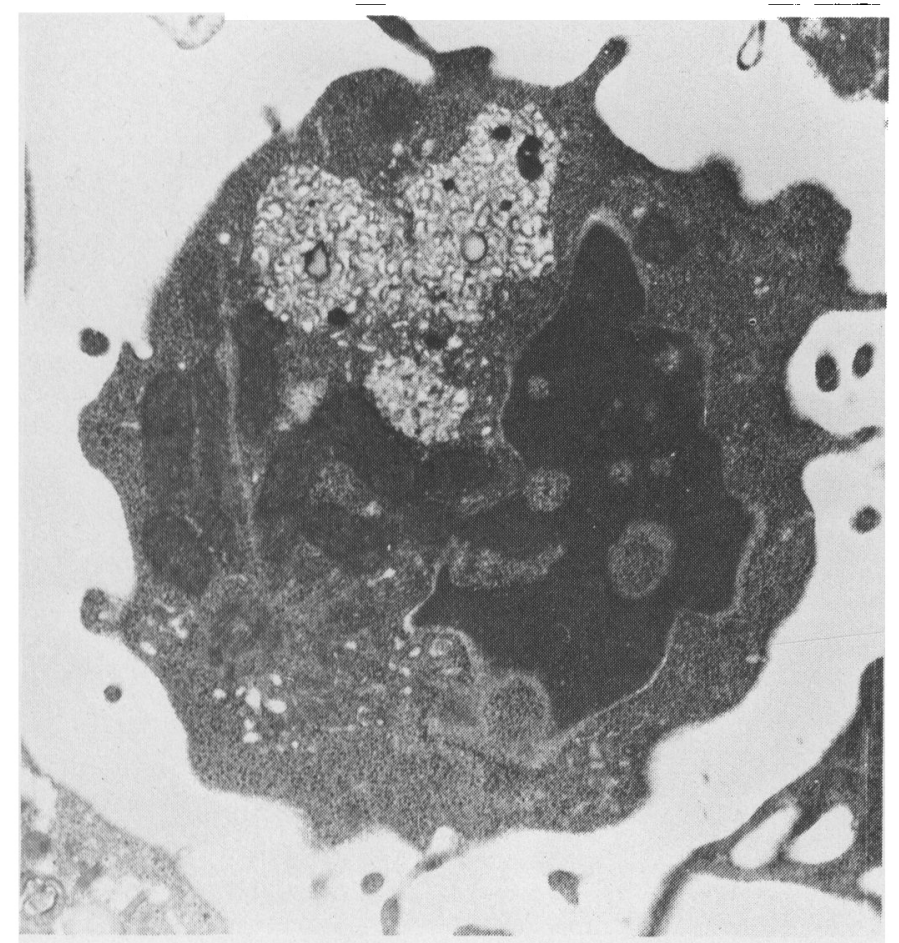

Figure 3-Ceroid lipofuscinosis, case 4. Lymphocyte containing curvilinear cytosomes. $x 24.000$

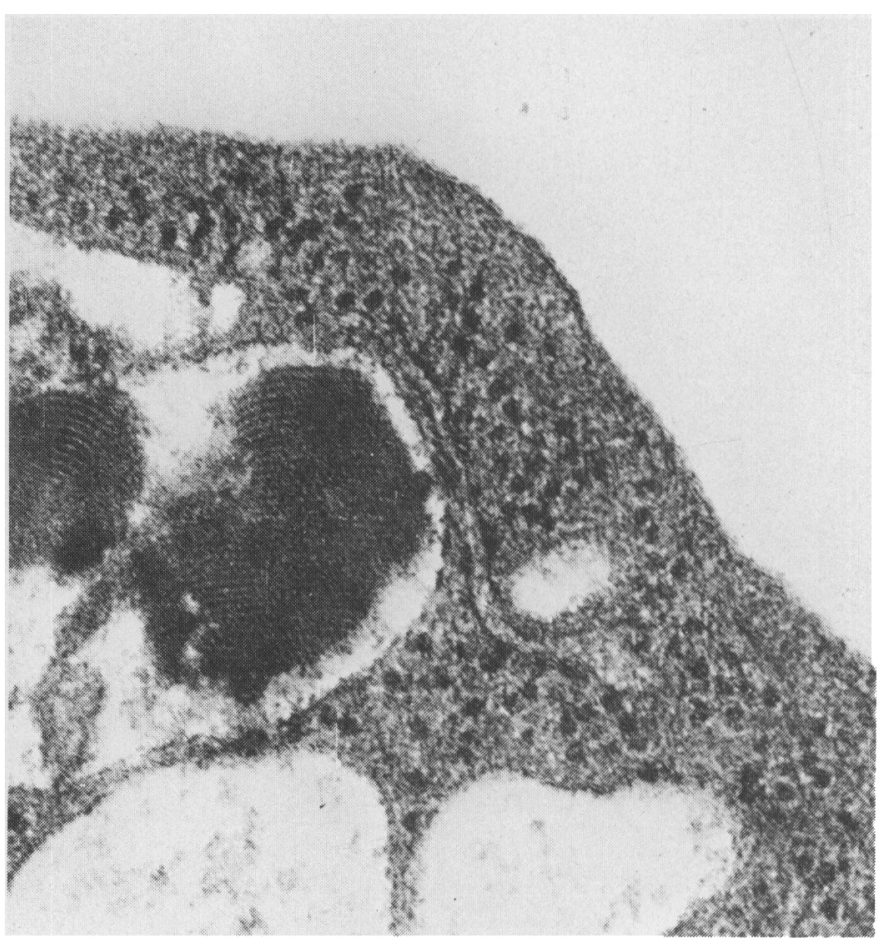

Figure 5-Ceroid lipofuscinosis, case 8. Vacuolated lymphocyte with fingerprint patterns. $x 118.800$
Figure 6-Ceroid lipofuscinosis, case 8. Lymphocyte with tubular and membranous shapes. $x 40.600$

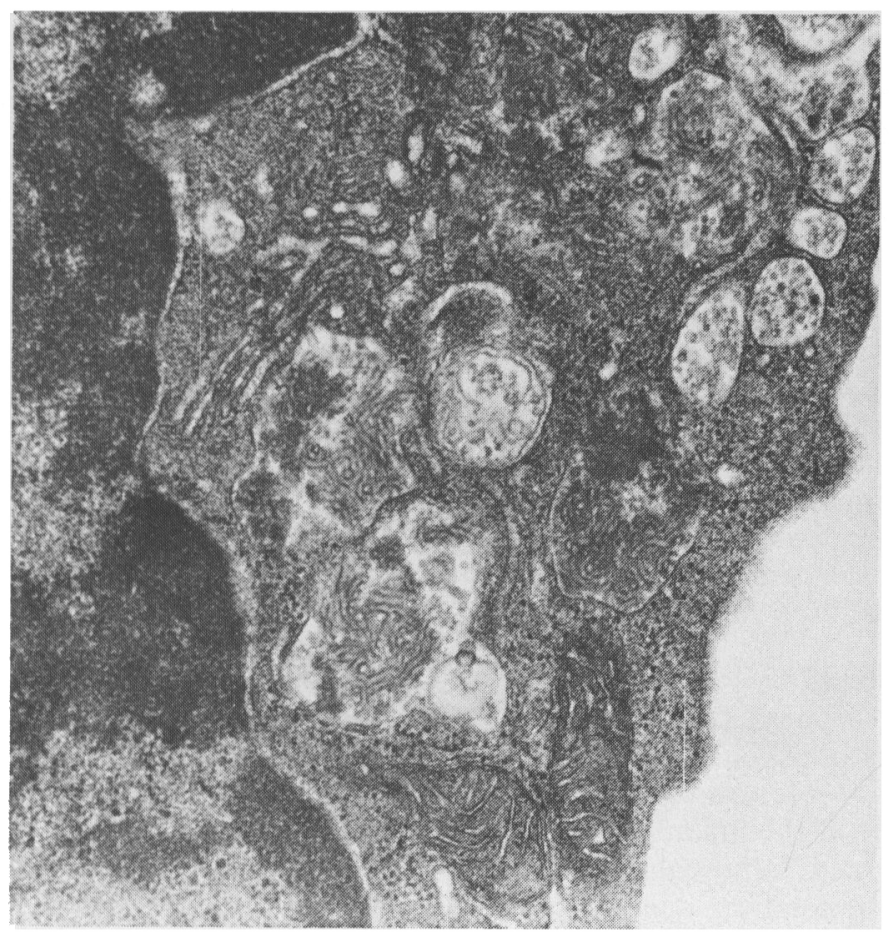

Figure 7-Ceroid lipofuscinosis, case 2a. (Father of patient with curvilinear cytosomes.) Lymphocyte with membranous and tubular inclusions. $x 72.000$

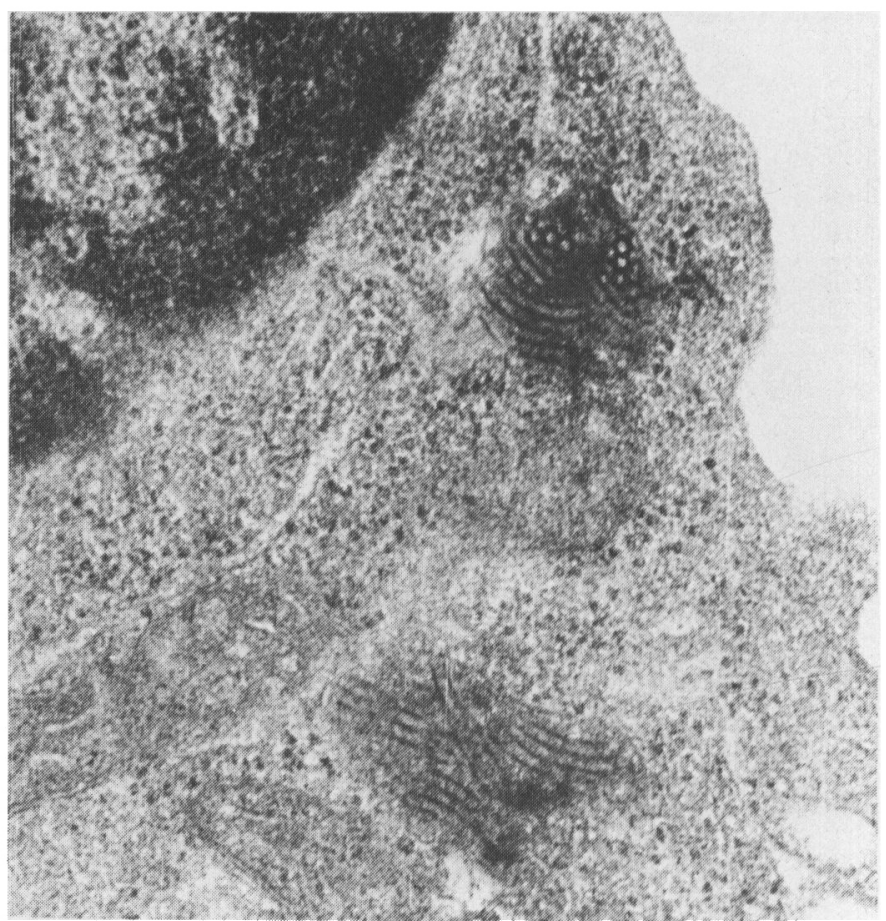




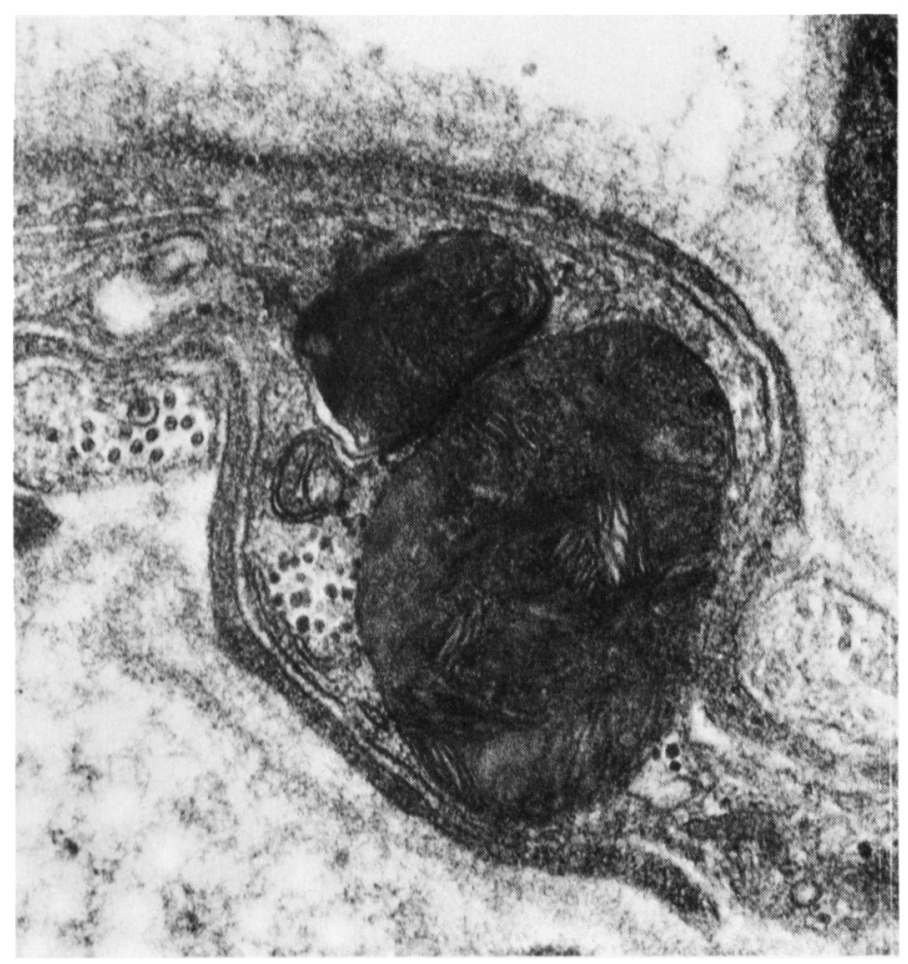

Figure 8-Late infantile $\mathrm{GM}_{2}$ gangliosidosis. Skin punch biopsy of six-year-old girl. Membrane-bound complex lipid deposits in unmyelinated axon. $x 72.6000$

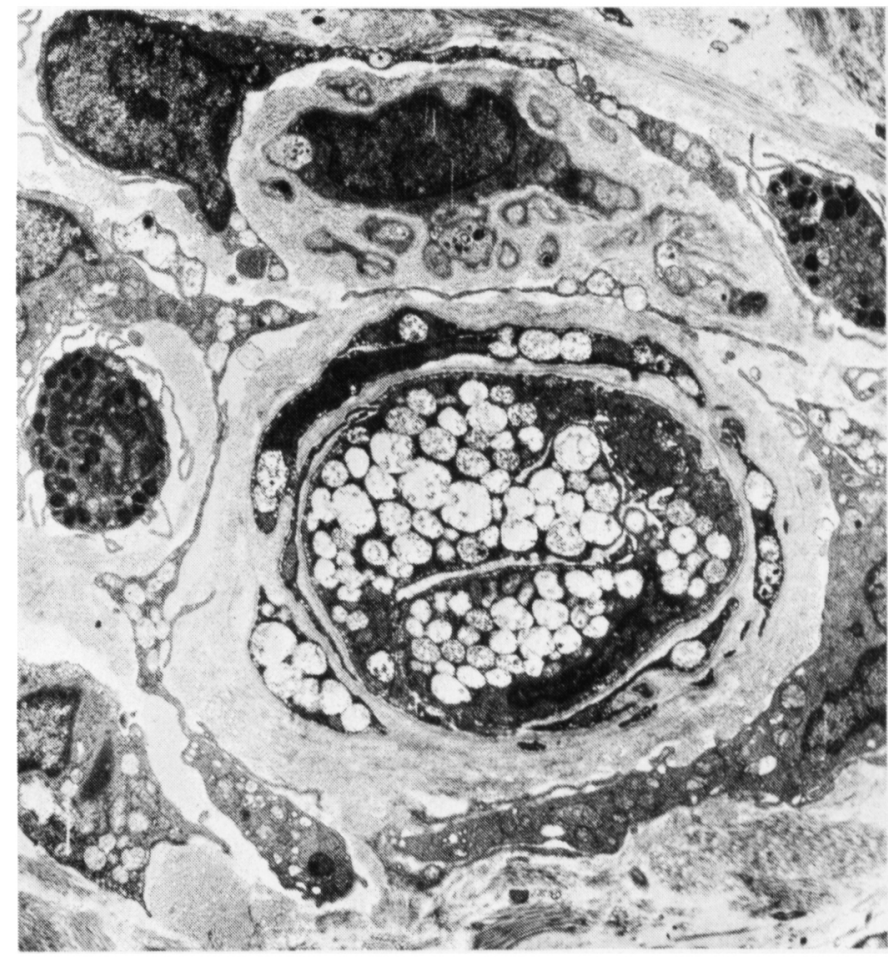

Figure 10-GM। gangliosidosis. Skin punch biopsy. A capillary is nearly obliterated because of marked vacuolation of endothelial cells. Perithelial cells and fibroblasts are also vacuolated. $x 5.600$

\section{$\mathrm{GM}_{2}$ GANGLIOSIDOSIS}

\section{(LATE INFANTILE)}

Two children were in this group, both adopted, one four, the other six years old. A clinical diagnosis of Tay Sachs disease had been made be-

Figure 9-Late infantile $\mathrm{GM}_{2}$ gangliosidosis. Skin punch biopsy of fouryear-old boy. Membranous cytoplasmic bodies in smooth muscle. $x 24.000$

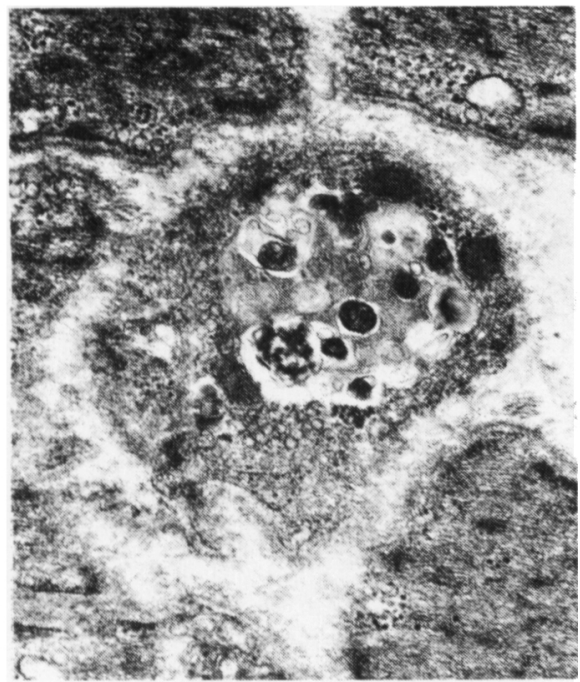

cause of regression, seizures and the presence of a cherry red spot on fundoscopic examination. The diagnosis was proven biochemically by deficiency in hexosaminidase $A$. The six-year-old girl had a rectal biopsy performed three years previously which showed bloated lipid filled neurons on light microscopy. Myelinated and unmyelinated axons in cutaneous nerves in skin biopsies of both children contained membrane bound, large, complex, lipid bodies (Fig. 8), identical to the structures encountered in neurons in gangliosidoses. The boy also had membranous cytoplasmic bodies in smooth muscles (Fig 9), a surprising finding, since extraneuronal storage is usually encountered only in Sandhoff's disease (hexosaminidase $A$ and $B$ deficiency).

\section{GM। GANGLIOSIDOSIS}

A skin punch biopsy from a 6-month-old girl with psychomotor retardation, hepatosplenomegaly and cherry red spots at the maculae, with severely reduced beta galactosidase, showed vacuolation of en- dothelial cells, perithelial cells, smooth muscle and fibroblasts (Fig. 10). In cutaneous nerves, complex lipid deposits were abundant in axons (Fig. 11). Skin biopsies from both parents were negative. Patients with $\mathrm{GM}_{1}$ gangliosidosis are known to have vacuolated lymphocytes (Lowden et al., 1973). Two blood samples of this girl were spoilt during handling and no other could be obtained. Blood samples from the parents showed vacuoles with membranes in monocytes, but this was not considered significant.

\section{GLOBOID LEUCODYSTROPHY}

A girl, whose sister died at eighteen months after mental regression, began to deteriorate and stiffen at about six months. Enzyme studies, a sural nerve biopsy and later autopsy confirmed the presence of globoid leucodystrophy. In a skin punch biopsy, the third grid and second cutaneous nerve examined showed a single suggestive crystal in a Schwann cell. Degeneration of the cutaneous nerves was not evident. 


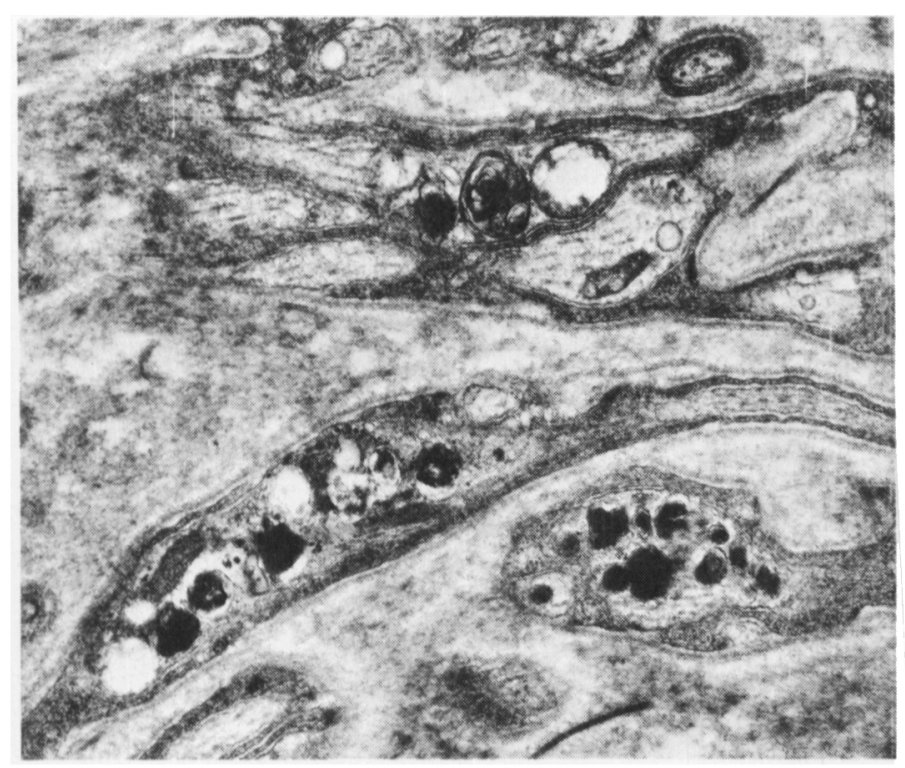

Figure II-GM1 gangliosidosis. Skin punch biopsy. Membranous cytoplasmic bodies in unmyelinated axons of small cutaneous nerve. $\times 20.300$

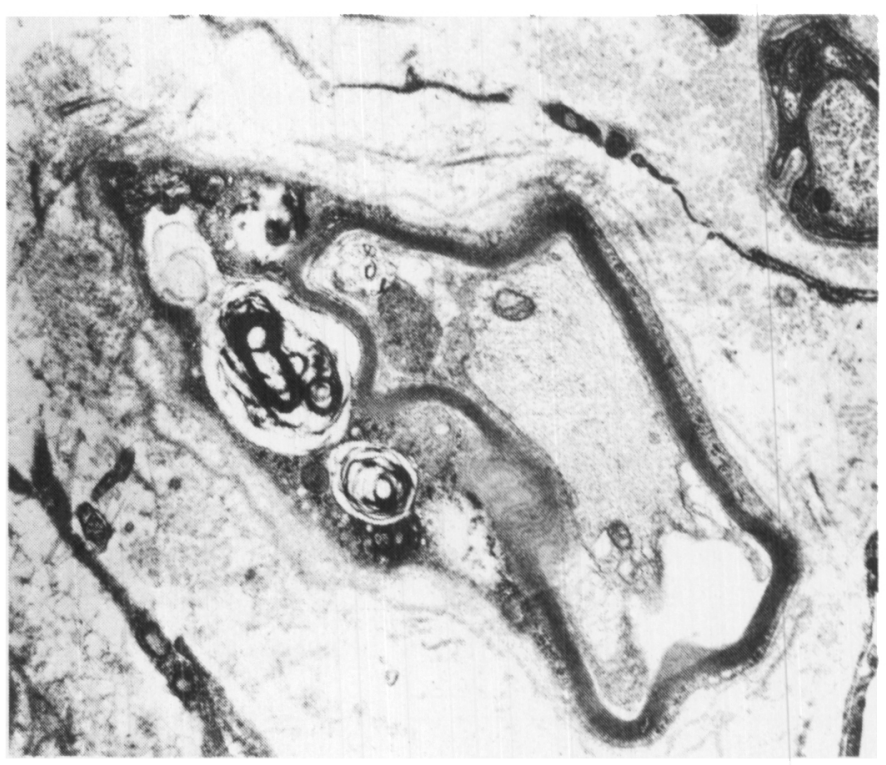

Figure 12-Metachromatic leucodystrophy. Skin punch biopsy. Myelinated axon with abnormally thin myelin sheath and myelin debris in Schwann cell. $x 14.800$

\section{METACHROMATIC \\ LEUCODYSTROPHY}

Two patients were examined. One was a twenty-one-year-old man on whom a diagnosis of metachromatic leucodystrophy had been made clinically and confirmed by severe reduction of arylsulphatase in a culture of fibroblasts. A cutaneous nerve in a skin punch biopsy showed degenera-

Figure 13-Metachromatic leucodystrophy. Skin punch biopsy. Arrays of parallel laminae of lipid in macrophage in cutaneous nerve. $x 31.100$

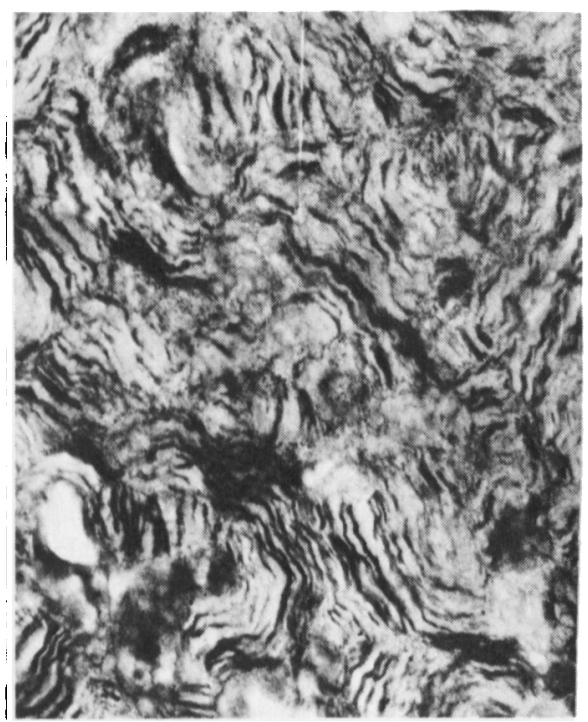

tion of myelinated fibers with accumulation of non-specific laminated myelin debris. The second was a fifteen-year-old girl with mental deterioration and slowing of nerve conduction. A sural nerve biopsy was positive for metachromatic material in macrophages in frozen and plastic embedded sections. Under the electron microscope degenerating nerve fibers and macrophages containing membrane bound collections of parallel stacked membranes were seen. In the skin punch biopsy, a cutaneous nerve showed a similar picture of degenerating myelinated fibers with myelin debris (Fig. 12), and macrophages packed with arrays of wavy parallel membranes

Figure 14-Adreno-leucodystrophy. Optic nerve at necropsy. Thin sheaves of lipid in macrophages. $x 40.600$

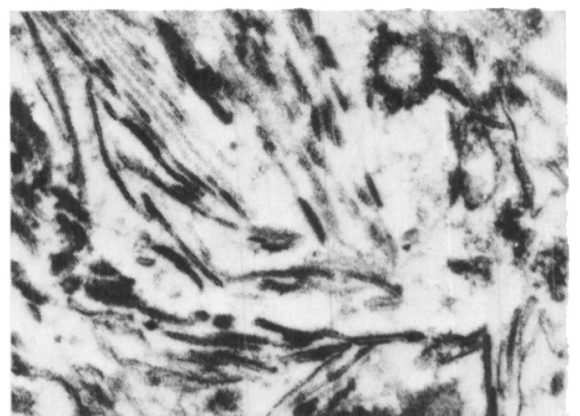

which represented the metachromatic material (Fig. 13). In a sample of blood, small myelin figures and vacuoles with membranes were found in occasional large mononuclear cells and this was deemed non-specific.

\section{ADRENO-LEUCODYSTROPHY}

A skin punch biopsy was obtained from an eleven-year-old boy, with a

Figure 15-Adreno-leucodystrophy. Skin punch biopsy. Laminated iipid in Schwann cell. $x 40.600$

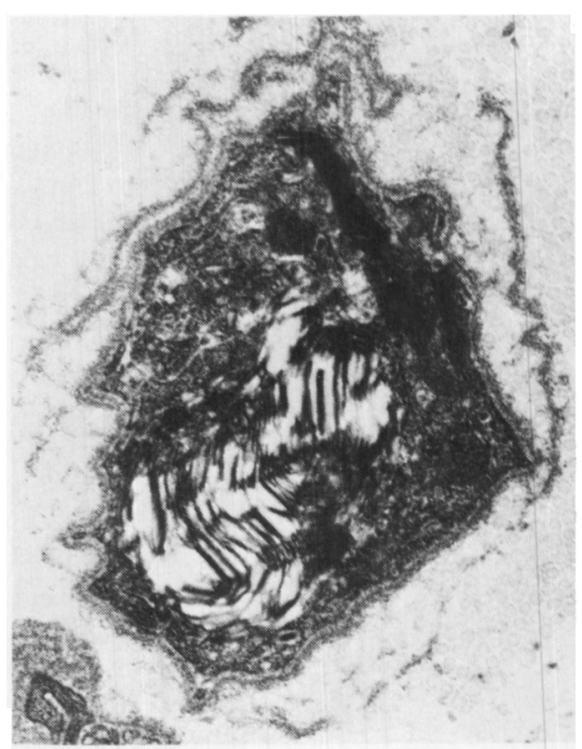


TABLE I

Biopsy Results in Ceroid Lipofuscinoses

\begin{tabular}{llll} 
Case & Tissues Examined & Morphology of Inclusions & Clinical Onset \\
\hline $\begin{array}{l}\text { Charles } \\
\text { N. }\end{array}$ & Rectal biopsy & $\begin{array}{l}\text { PAS Positive neurons light } \\
\text { microscopy } \\
\text { curvilinear cytosomes }\end{array}$ & Late Infantile \\
& $\begin{array}{l}\text { Skin } \\
\text { Lymphocytes } \\
\text { Blood smear }\end{array}$ & $\begin{array}{l}\text { curvilinear cytosomes } \\
\text { no vacuoles }\end{array}$ &
\end{tabular}

2. Dale C. Fibroblasts

Skin curvilinear cytosomes

Lymphocytes curvilinear cytosomes

\section{2a. Father Skin negative}

C. Lymphocytes fingerprints, tubules

2b. Mother Skin negative

C.

3. Steven Brain biopsy

P. Skin

Lymphocytes

curvilinear cytosomes

curvilinear cytosomes

curvilinear cytosomes

3a. Father Skin

P. Lymphocytes

Blood smear

negative

tubules, long membranes

vacuoles

3b. Mother Skin

P. Lymphocytes

negative

tubules

4. Brian S. Skin

Lymphocytes

curvilinear cytosomes

curvilinear cytosomes

Late infantile

5. Sandra Skin

$P$.

Fibroblasts

(sister

negative

Late infantile

curvilinear)

6. Karen A. Rectum-muscle, osmiophilic granular

7. Michael Brain

S. Skin

Randy Skin

B. Lymphocytes

9. Andrew Skin

W.

10. Edward Brain biopsy M. endothelium deposits, a few rectilinear

short membranes

Lymphocytes

osmiophilic granular deposits

Blood smear

vacuoles

Lymphocytes

osmiophilic granular deposits

osmiophilic granular deposits

Late infantile

Fibroblasts

osmiophilic granular deposits

tubules, long membranes

Juvenile

fingerprints, tubules

negative

Lymphocytes

curvilinear cytosomes

tubules

Blood smear

fingerprints

vacuoles fingerprints, granular deposits

long membranes, fingerprints,

tubules

fingerprints

vacuoles
Late infantile

Microcephalic

Lymphocytes

Blood smear family history of two grand-uncles and an uncle dead of 'Schilder's disease." The patient himself died a few weeks after biopsy and the typical thin, sheaf-like structures, described by Powers and Schaumburg (1974), were found on electron microscopy of the severely degenerated white matter (Fig. 14), and in vacuolated adrenal cortical cells. The skin punch biopsy demonstrated degenerating myelinated fibers in cutaneous nerves. Schwann cells contained laminated lipid (Fig. 15 which, however, was thought to be probably non-specific.

\section{GAUCHER'S DISEASE}

Three patients had Gaucher's disease, all proved by bone marrow biopsy. None had clinical neurological involvement. In one patient only white cells were available, in the others, skin and white blood cells were examined. No specific storage products could be identified.

\section{DISCUSSION}

Skin punch biopsies and white blood cell examination are useless in Gaucher's disease. Whilst a probably positive biopsy was obtained in globoid leucodystrophy, the results were meagre and only obtained with great difficulty. This method is less rewarding than sural nerve biopsy or chemical analysis where this is available. In adreno-leucodystrophy and metachromatic leucodystrophy, some degenerative changes were seen in cutaneous nerves. However, with the exception of one patient with metachromatic leucodystrophy, the lesions were not pathognomonic.

In gangliosidoses, the exact diagnosis is obtained biochemically. If a tissue diagnosis is required, however, a simple skin punch biopsy yields reliable results, by demonstrating complex membranous cytoplasmic bodies within axons in cutaneous nerves. In GM। gangliosidosis, there is also prominent cytoplasmic vacuolation of endothelial and perithelial cells, fibroblasts and smooth muscle. These findings match those described in tissues of such children at necropsy (Lowden et al., 1973). 
The greatest diagnostic value is in patients with neurovisceral ceroid lipofuscinoses, since no biochemical tests are available at present. Both skin biopsies and lymphocytes are uniformly positive, and both methods are easily performed procedures with little inconvenience to the patient. The preparation of the blood is more difficult than the handling of the skin punch biopsy and requires the proximity of a laboratory. On the other hand, a blood sample is least painful for the patient and yields a positive diagnosis with little effort for the electron microscopist. Positive results were obtained from the blood of parents, although with considerably more difficulty, while skin biopsies were negative. It is worth noting here, that parents of children with curvilinear cytosomes, had fingerprint and tubular patterns. This suggests that all forms of this disease are based on an identical inborn error of metabolism and that the shape of the inclusions is tied, perhaps, to the severity of the disorder.

\section{REFERENCES}

BAGH, K. V. and HORTLING, A. M. (1948). Blood findings in juvenile amaurotic idiocy. Nordisk Medicin, 38, 1072.

CARPENTER, S., KARPATI, G. and ANDERMANN, F. (1972). Specific involvement of muscle, nerve and skin in late infantile and juvenile amaurotic idiocy. Neurology, 22, 170-186.

CARPENTER, S., KARPATI, G., WOLFE, L. S. and ANDERMANN, F. (1973). A type of juvenile cerebromacular degeneration characterized by granular osmiophilic deposits. Journal of Neurological Science, 18, 67-87.

DEKABAN, A. S. and HERMAN, M. M. (1974). Childhood, juvenile and adult lipidoses. AMA Archives of Pathology, 97, 65-73.
HALTIA, M., RAPOLA, J. and SANTAVUORI, P. (1973). Infantile type of socalled neuronal ceroid lipofuscinosis. Acta Neuropathologica, 26, 157-170.

LOWDEN, J. A., CUTZE, CONEN, P. E., RUDD, N. and DORAN, T. A. (1973). Prenatal diagnosis of $\mathrm{GM} /$ gangliosidosis. New England Journal of Medicine, 288, 225-228.

MARTIN, J. J. and JACOBS, J. J. (1973). Skin biopsy as a contribution to diagnosis in late infantile amaurotic idiocy with curvilinear bodies. European Neurology, 10, 281-291.

POWERS, J. M. and SCHAUMBURG, H. H. (1974). Adreno-leucodystrophy. AMA Archives of Neurology, 30, 406-408.

WITZLEBEN, C. L., SMITH, K., NELSON, J. S., MONTELEONE, P. L., and LIVINGSTON, D. (1971). Ultrastructural studies in late onset amaurotic idiocy Lymphocytic inclusions as a diagnostic marker. Journal of Pediatrics, 79, 285-293.

WITZLEBEN, C. L. (1972). Lymphocyte inclusions in late onset amaurotic idiocy. Value as diagnostic test and genetic marker. Neurology, 22, 1075-1078. 